\title{
LA TRIBUTACIÓN AMBIENTAL COMO RESPUESTA A LOS DESAFÍOS ECOLÓGICOS DE LOS MUNICIPIOS ARGENTINOS: PRINCIPALES DIFICULTADES ${ }^{1}$
}

ENVIRONMENTAL TAXATION AS A TOOL FOR THE ECOLOGICAL CHALLENGE OF ARGENTINEAN MUNICIPALITIES: MAIN DIFFICULTIES

RODOLFO SALASSA BOIX

UNIVERSIDAD NACIONAL DE CÓRDOBA ARGENTINA 


\title{
RESUMEN
}

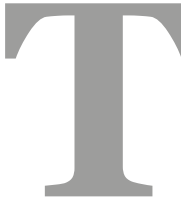

eniendo en cuenta que los municipios argentinos padecen diferentes problemáticas ambientales, que son el nivel de gobierno más idóneo para promover la protección del medio ambiente y que el Derecho tributario ofrece un gran aporte en esta materia, el objeto de este trabajo estriba en analizar dos de las principales dificultades normativos que, a nuestro juicio, enfrentan los municipios a la hora de dictar medidas tributarias ambientales. Una vez sorteadas estas dificultades se allanará el camino para poder recurrir a la Tributación Ambiental como una alternativa jurídica más para los municipios a la hora de enfrentar los problemas ecológicos que les aquejan. A raíz de ello, y sin pretender agotar todas las posibles dificultades jurídicas que presenta esta temática, el desarrollo del trabajo gira en torno a dos tipos de obstáculos. Uno de carácter sustancial, que hace a la falta de conocimiento sobre la naturaleza jurídica de las medidas tributarias ambientales y otro de carácter formal, que hace a la competencia tributaria que tienen estos entes locales para regular tales medidas.

Palabras Claves: doble imposición; poder fiscal; recursos municipales; política sustentable.

\begin{abstract}
Considering that Argentine municipalities suffer different ecological local problems, that they are the best positioned level of government to promote environmental protection and that Tax Law provides an appreciable contribution in this regard, the purpose of this paper is to analyze two of the main regulatory difficulties and obstacles that municipalities face to regulate environmental taxation measures. Once we resolve these difficulties we could consider the environmental taxation as a legal alternative for municipalities to face their ecological problems. According to that, without attempting to exhaust all possible legal difficulties in this regard, the analysis is focuses on two types of obstacles: the substantial one, related with the lack of awareness of the legal nature of environmental tax measures, and the formal one, related with tax municipal power to regulate such kind of measures.
\end{abstract}

Keywords: double imposition; tax power; municipal resources; sustainable policy.

\footnotetext{
${ }^{1}$ El presente trabajo se enmarca dentro del proyecto de investigación titulado "La Fiscalidad Ambiental en el ordenamiento jurídico argentino a partir del marco de la Constitución Nacional” (2016-17), dirigido por el Dr. Rodolfo Salassa Boix y aprobado y financiado por la Secretaría de Ciencia y Tecnología de la Universidad Nacional de Córdoba, Argentina (Secyt).
} 


\section{INTRODUCCIÓN}

La preocupación por el deterioro ecológico ha instado a los Estados, y a sus diferentes niveles de gobierno, a llevar adelante diferentes medidas para detener, o al menos reducir al mínimo, esta problemática. Estas medidas son las que llamamos "mecanismos estatales de protección ambiental” (MEPA), que podemos definir como todos aquellos instrumentos jurídicos que pueden adoptar las Administraciones, dentro del ejercicio de su función pública, para preservar el medio ambiente (Salassa Boix, 2013a y 2013c). ${ }^{2}$

Evidentemente la Argentina no es ajena a esta preocupación y a la necesidad de hacer frente a las diferentes problemáticas ambientales, las cuales afectan a sus distintos niveles de gobierno, en especial a los de carácter local (inundaciones, sequías, calidad del aire, desforestación, contaminación acústica y paisajística, etc.).

Dentro de los diferentes niveles de gobierno se puede afirmar que los municipios "por encontrase... en contacto más directo con los grupos poblacionales de similares necesidades y valores es... la órbita de gobierno más idónea para ocuparse de la protección de medio ambiente" (Ameriso, Beren, Ferullo \& Sevilla, 1999, p. 467) . En este sentido también se ha dicho que "cuestiones como el transporte, la vivienda, el manejo de residuos, la limpieza urbana, los espacios públicos verdes, el suministro y uso de energía, etc., constituyen grandes dilemas que deberían -en su mayor medida- ser resueltos por parte de los gobiernos locales. No sólo en el orden económico y de planificación, sino también en el aspecto ambiental" (Galarza y Fraga, 2009, p. 1). Hoy en día, gran parte de los municipios argentinos padece numerosas y complejas emergencias ecológicas que prometen profundizarse en un futuro no muy lejano si no se actúa con rapidez, y es el Derecho, en este caso el tributario, el que está llamado nuevamente a brindar soluciones (Lepori, 2013, p. 1). ${ }^{3}$

Dentro del amplio espectro de posibilidades que ofrece el ordenamiento jurídico las medidas fiscales vienen cobrando un protagonismo cada vez mayor. De hecho, en las últimas décadas la mayoría de Estados miembros de la Organización para la Cooperación y el Desarrollo Económicos (OCDE), con los países nórdicos a la cabeza, ha impulsado algún tipo de reforma fiscal verde. Es decir que son numerosas, y de público conocimiento, las experiencias internacionales que avalan la importancia, e incluso la necesidad, de recurrir al Derecho tributario para enfrentar la contaminación ambiental.

La actividad financiera del Estado, definida como aquella actividad encaminada a la obtención de ingresos y realización de gastos para satisfacer las necesidades públicas, ha ido evolucionando y utilizando nuevos métodos de actuación acorde a los objetivos perseguidos. Así las cosas, dicha actividad no se limita únicamente a la obtención de sumas de dinero, para

\footnotetext{
${ }^{2}$ Otros autores definen a los MEPAS como "toda la panoplia de técnicas de prestación, de limitación y de fomento que arbitra el ordenamiento jurídico" (Lozano Cutanda, 2007, p. 100).

${ }^{3}$ También se explica por "la relación directa entre la actividad de las ciudades y la afectación del medio ambiente, y de las competencias que los municipios detentan en ciertas materias que observan estrecha vinculación con la ambiental" (Almada y Matich, 2011, p. 92).
} 
luego financiar gastos públicos, sino que también se utiliza para la consecución de otros fines constitucionalmente legítimos y exigibles. Entre estos fines se encuentra la protección del medio ambiente. ${ }^{4}$

Teniendo en cuenta que los municipios argentinos padecen diferentes problemáticas ambientales, que son el nivel de gobierno más idóneo para promover la protección del medio ambiente y que el Derecho tributario ofrece un gran aporte en esta materia, el objeto de este trabajo estriba en analizar dos de las principales dificultades normativos que, a nuestro juicio, enfrentan los municipios a la hora de dictar medidas tributarias ambientales. Una vez sorteadas estas dificultades se allanará el camino para poder recurrir con a la Tributación Ambiental como otra alternativa jurídica en el ámbito municipal a la hora de enfrentar los problemas ecológicos que les aquejan.

A raíz de ello, y sin pretender agotar todas las posibles dificultades jurídicas que presenta esta temática, el desarrollo del trabajo gira en torno a dos tipos de dificultades u obstáculos. Uno de carácter sustancial, que hace a la falta de conocimiento sobre la naturaleza jurídica de las medidas tributarias ambientales, ya que mal pueden los municipios regular medidas cuya esencia y naturaleza jurídica desconocen. Otro de carácter formal, que hace a la competencia tributaria que tienen estos entes locales para regular tales medidas. En esta parte se desarrollará la naturaleza jurídica de los municipios, su capacidad para dictar tributos y las limitaciones que afectan dicha capacidad a partir del régimen de coparticipación federal de tributos.

\section{METODOLOGÍA}

El trabajo analiza dos de los principales obstáculos jurídicos que enfrentan actualmente los municipios argentinos a la hora de dictar medidas tributarias ambientales. Este análisis se basa en una visión esencialmente dogmática del Derecho con una fuerte relación interdisciplinar entre el Derecho constitucional, el Derecho tributario y el Derecho ambiental. De esta manera, la meta fue comprender primero, en base al material recolectado, y explicar después el significado de las normas positivas vigentes sobre la legislación de las medidas tributas ambientales, para finalmente arribar a las conclusiones.

Para explicar el significado de las normas positivas vigentes se llevó adelante un riguroso trabajo de interpretación organizado en dos etapas. La primera, de tipo heurística, que implicó la recopilación y clasificación de la documentación relevante sobre el tema. La segunda, de tipo hermenéutica, que consistió en la interpretación de la información recopilada mediante la teoría de la argumentación.

${ }^{4}$ En nuestra Constitución Nacional debemos recurrir fundamentalmente a los artículos 41 y 43. 
En esta última etapa nos valimos de la interpretación literal, sistemática y teleológica, aunque fundamentalmente en estas últimas dos. En primer lugar, puesto que las normas jurídicas se encuentran constituidas por enunciados lingüísticos, era imprescindible partir del significado literal de las palabras. En segundo lugar, atento que las medidas tributarias ambientales presentan una elevada "transversalidad" dentro del ordenamiento jurídico, en especial en el Derecho constitucional, el Derecho tributario y el Derecho ambiental, entendemos que para comprender correctamente los preceptos legales que se les aplican era necesario relacionarlos con las demás disposiciones del sistema legal. En tercer lugar, analizamos las normas de acuerdo a su finalidad.

\section{OBSTÁCULO SUSTANCIAL: NOCIÓN Y CARACTERÍSTICAS BÁSICAS DE LAS MEDIDAS TRIBUTARIAS AMBIENTALES}

Las medidas tributarias ${ }^{5}$ (tributos ambientales y beneficios fiscales) se encuentran insertas dentro del Derecho tributario y pueden relacionarse con el medio ambiente de tres maneras: perjudicándolo, beneficiándolo o siendo indiferente a éste. Es por ello que respectivamente nos referimos a tributos y beneficios fiscales que: a) protegen al medio ambiente (área del Derecho tributario que se conoce como "Tributación Ambiental"); b) que atentan contra el medio ambiente (área a la que llamaremos "Tributación Anti-ambiental" a los fines de este trabajo) y c) que son indiferentes a éste (área a la que llamaremos "Tributación No-ambiental"). A partir de allí, podemos decir que la Tributación Ambiental es aquella área del Derecho tributario que comprende aquellos tributos y beneficios fiscales que respectivamente dirigen a los contribuyentes a evitar la realización de conductas desfavorables para el medio ambiente y realizar conductas favorables para éste. El trabajo se focaliza en la Tributación Ambiental, razón por la cual a continuación veremos sucintamente por separado cada una de estas medidas fiscales que la integran.

\subsection{Tributos ambientales}

Los tributos ambientales se encuentran dentro de la órbita de los gravámenes con fines extrafiscales, y son aquéllos cuya finalidad principal va más allá de lo estrictamente recaudatorio. Podemos definirlos entonces como aquellos gravámenes que no tienen como finalidad esencial obtener recursos sino el desaliento de conductas o bienes que atentan contra el medio ambiente, en el caso de los impuestos, o la prestación o realización de servicios u obras públi- 
cas ambientales, en el caso de las tasas y contribuciones especiales, más allá de la asignación presupuestaria de los fondos (Salassa Boix, 2013, p. 186). A raíz de esta definición podemos decir que los impuestos ambientales son los tributos ambientales más idóneos para modificar la conducta contaminante de los contribuyentes.

Los tributos ambientales incluyen a las tres especies tributarias: los impuestos, las tasas y contribuciones especiales. Atento que la definición de tributos ambientales se basa en el hecho imponible, y su capacidad para modificar conductas, en el caso de los impuestos este hecho se basa en la conducta contaminante de los contribuyentes, mientras que en las tasas y contribuciones especiales se sustenta en la conducta de la Administración, en este caso municipal, ya sea prestando un servicio o realizando una obra favorable para el medio ambiente. Esto se relaciona con la clasificación de tributos vinculados (impuesto) y no vinculados (tasa y contribución especial).

A diferencia de los tributos no vinculados, los vinculados, cuyo pago está directamente relacionado con una actividad estatal, exigen una necesaria asignación específica de fondos para prestar un servicio público o llevar adelante una obra pública de carácter ambiental. Esta necesidad no obedece a su carácter de "ambiental" sino más bien a su carácter de tributos "vinculados”. Es por ello que una definición genérica de tributos ambientales debe remarcar la irrelevancia del destino de los fondos. A continuación veremos los elementos definitorios que se desprenden de la definición de tributos ambientales que vimos ut supra.

\subsubsection{Pertenencia a la categoría de tributos}

Más allá que su finalidad principal sea de carácter intervencionista (no recaudatoria), estos gravámenes pertenecen al género amplio de tributos y, dentro de éste, a la sub-especie de tributos con fines extrafiscales. En virtud de ello, como todo gravamen, deben contar con los elementos que conforman el hecho imponible de cualquier tributo (objetivo, subjetivo, temporal, espacial y elementos cuantificantes) ${ }^{6} \mathrm{y}$ regirse por las mismas limitaciones y principios fiscales que determina la Carta Magna. ${ }^{7}$

\subsubsection{Finalidad principal de carácter extra-fiscal}

Los tributos ambientales adoptan como finalidad principal el desaliento de conductas o bienes anti-ecológicos y como finalidad secundaria la obtención de recursos económicos. Esto

\footnotetext{
${ }^{6}$ "Se deduce que la naturaleza extrafiscal del tributo debe estar presente en el hecho generador, la base gravable, el sujeto pasivo y la tarifa del tributo, debe desprenderse de cada uno de los elementos estructurales del impuesto, y, por ello, el carácter de desincentivo de determinadas conductas... debe ser coherente con la obligación tributaria" (Rozo Gutiérrez, 2003, p. 170).

7 "Las funciones extrafiscales del tributo han de ser constitucionales, en el sentido de que el legislador podrá establecer tributos no recaudatorios, siempre que se trate de proteger otros valores constitucionalmente tutelados, lo cual no implica que sea desnaturalizado el tributo de los principios constitucionales..." (Rozo Gutiérrez, 2003, p. 170).
} 
quiere decir que no se despoja al gravamen de su finalidad recaudatoria, sólo que ésta se ve eclipsada por el objetivo primordial del tributo (extrafiscal). "La vía impositiva puede resultar un fin secundario para la obtención de recursos", siendo ello lo que "permite precisar la utilización del tributo con fines de política económica” (Díaz, 2008, p. 5).

Para que exista una verdadera finalidad ecológica el gravamen tiene que poseer una entidad tal que altere sensiblemente las alternativas de los posibles agentes contaminantes. No basta con la mera sujeción de una actividad o bien contaminante sino que la presión tributaria tiene que ser de una cuantía tal que al contribuyente no le dé lo mismo agredir el medio ambiente que no hacerlo (Salassa Boix, 2015). Ello nos obliga a analizar cada caso en particular con una necesaria evaluación ex ante y ex post.

Hoy en día aún existe un sector de la doctrina minoritario que suele afirmar que en el resultado ideal de los tributos con fines extrafiscales sería alcanzar a una recaudación nula, ya que así se habrá conseguido el objetivo regulador pretendido (López Espadafor, 2007). Si entendemos a la "extrafiscalidad" como "no recaudación" caemos en un desacierto conceptual, ya que ningún tributo, por más extrafiscales que sean sus fines, procura (o debería procurar) una recaudación cero. La ausencia total de recaudación implica inexistencia de conducta gravada y este objetivo no debe buscarse a través de un tributo sino mediante figuras prohibitivas acompañadas de controles administrativos y medidas sancionadoras eficaces (Magadán Díaz \& Rivas García, 2004).

\subsubsection{Ausencia de naturaleza sancionatoria}

$\mathrm{Si}$ afirmamos que un tributo con fines extrafiscales conserva su finalidad recaudadora y que se aplica sobre conductas tolerables por la sociedad pero es conveniente su morigeración, éste nunca podrá tener naturaleza sancionatoria. Es por ello que el binomio infracciónsanción no se muestra adecuado para regular tales situaciones (Varona Alabern, 2010). Un tributo presupone el acaecimiento del hecho imponible mientras que una sanción presupone la comisión de una infracción, y la realización del hecho imponible nunca puede tener tal carácter. "Mientras en las multas debe haber una conducta antijurídica (violación a una ley), en los tributos disuasivos no habría norma violada" (Schindel, 2003, p. 567).

\section{d) Falta de necesidad de una asignación específica de los fondos}

Los tributos con fines extrafiscales no dependen, para considerarse tales, de la aplicación de los fondos obtenidos a la finalidad extrafiscal perseguida. Ello no quiere decir que no sea posible encontrar tal aplicación (incluso la alentamos), sino que no se trata de un requisito distintivo en este tipo de gravámenes.

El Derecho financiero comprende al Derecho tributario, Derecho presupuestario, Derecho de la deuda pública y Derecho del patrimonio público (Herrera Molina, 2001). El Derecho 
tributario sólo se ocupa de los recursos tributarios que constituyen una de las tipologías de ingresos de Derecho público y, si estamos dentro del Derecho tributario, cualquier clasificación propuesta debe versar sobre su objeto de estudio y no sobre los gastos. La extrafiscalidad está en el desaliento de una conducta o situación pero no en el hecho que los recursos sean destinados a la finalidad extrafiscal. Si confundimos esto se puede caer en el error de catalogar como extrafiscales a tributos que en realidad no lo son, ya que el hecho imponible no cumple con su función motivadora o disuasoria. Esto no impide que podamos clasificar a los tributos según el destino de sus fondos, y allí podremos hablar de gravámenes cuya recaudación, más allá de su hecho imponible, tiene un destino ambiental o no.

\subsection{Beneficios fiscales ambientales}

Los beneficios fiscales ambientales son aquellas ventajas tributarias que persiguen anular, aminorar o aplazar el pago de un gravamen a los fines de incentivar la realización o utilización de actividades o bienes favorables para el medio ambiente (Salassa Boix, 2015).

Tanto los tributos ambientales como los beneficios fiscales ambientales son instituciones propias del Derecho tributario que bregan por la preservación del medio ambiente. En líneas generales, la gran distinción entre estas dos medidas estriba en que mientras los tributos ambientales persiguen desmotivar a los administrados en la realización de conductas anti-ambientales (desalentando el consumo desmedido del agua, la utilización excesiva de los automóviles, la liberación de emisiones contaminantes, etc.), los beneficios fiscales ambientales procuran alentar la realización de conductas pro-ambientales (promoviendo la utilización de energía limpia, el uso de vehículos menos contaminantes, la reforestación de bosques, etc.).

\section{OBSTÁCULO FORMAL: COMPETENCIA TRIBUTARIA DE LOS MUNICIPIOS PARA DICTAR MEDIDAS FISCALES AMBIENTALES}

\subsection{Naturaleza jurídica de los municipios}

Antes de abordar la competencia tributaria de los municipios es necesario indagar brevemente sobre su naturaleza jurídica como uno de los niveles de gobiernos que forman nuestro sistema federal de gobierno y las implicancias que de ella se derivan para el tema que nos ocupa. Durante mucho tiempo diversos exponentes de la doctrina y jurisprudencia discutieron acerca de esta cuestión, polarizándose el debate entre quienes defienden únicamente la autarquía y los que apoyan la autonomía municipal. ${ }^{8}$

\footnotetext{
${ }^{8}$ También encontramos posturas intermedias que niegan una "autonomía municipal sin límites" y una "autarquía a raja tabla", lo que lleva a su defensores a hablar de "autonomía relativa" (Cogorno, 2009, p. 5).
} 
García Belsunce (1995) sostiene que la autonomía supone un poder de legislación propio y originario, que algunos llaman constituyente. Es la facultad de darse sus propias instituciones y de gobernarse por ellas mismas. La autarquía implica un poder de legislación delegado y derivado. El ente autárquico tiene atribuciones para administrarse a sí mismo, pero de acuerdo con una norma que le es impuesta, pues el ente no tiene poderes para dictar dicha norma. Lo que caracteriza al ente autónomo, y lo diferencia del autárquico, no es la extensión de atribuciones sino el origen de éstas y que sean propias del ente. La autonomía es un concepto político y no administrativo mientras que la autarquía es un concepto administrativo y no político.

Los autores que avalan la autarquía municipal se basan a grandes rasgos en la falta de atribución expresa respecto de los municipios para darse sus cartas orgánicas, en la sumisión a un contralor jurisdiccional (Bielsa, 1962) y en que aceptar la autonomía implicaría la absurda pretensión de consentir una suerte de provincias menores dentro de las auténticas y genuinas provincias (Revilla, 2001).

Los defensores de la autonomía municipal sostienen en líneas generales que el municipio no nace como un desglose de competencias provinciales sino que es una forma primaria de descentralización política, y no sólo administrativa, con una genuina autonomía por inmediata operatividad de la Constitución Nacional (Bidart Campos, 1994). Asimismo, en el ámbito fiscal, se ha dicho que todos los niveles de gobierno tienen facultades tributarias de la misma naturaleza jurídica, sin que puedan establecerse grados o jerarquías entre ellas. Todos ellos tienen poder originario o inherente, porque él es connatural al Estado en cualquiera de sus manifestaciones (Giuliani Fonrouge, 1993).

En esta oportunidad nuestra intención no es profundizar sobre los argumentos de cada una de estas posturas; mucho menos luego de la reforma constitucional de 1994 que prácticamente zanjó esta cuestión. El actual artículo 123 de la CN, cuyo contenido se debe a la evolución pretoriana de la Corte Suprema de Justicia de la Nación (CSJN), puso fin a este extenso debate y consolidó la postura de la autonomía municipal. A continuación repasamos sucintamente las etapas de tal evolución.

En una primera etapa (1911-1928) el Alto Tribunal afirmó que los municipios son meras delegaciones de los poderes provinciales circunscriptas a fines y límites administrativos, que la $\mathrm{CN}$ ha previsto en su artículo 5 como entidades de las Provincias y sujetas a la legislación de éstas (F. 114:282). En la segunda etapa (1929-1943) la Corte sostuvo que las municipalidades son organismos de carácter esencial con un ámbito propio para administrar (F. 154:25). En la tercera etapa (1944-1988) el Máximo Tribunal señaló que los municipios tienen la organización que les asigna cada Provincia, pues la Carta Magna nada ha previsto al respecto, con excepción de lo establecido en su artículo, en el sentido de exigir que se asegure el régimen municipal, siendo propio de los gobiernos provinciales fijar el sistema económico administrativo de las comunas (F. 199:423). En la cuarta etapa (1989 en adelante) la CSJN estableció obiter dicta que los Municipios son entidades autónomas, determinando que a partir de 1957, con las 
modificaciones producidas a las constituciones provinciales, había sido dejada de lado la tesis autárquica (F. 312:327).

A partir de ello coincidimos con Naveira de Casanova (2001) cuando sostiene que luego de la reforma constitucional de 1994 el artículo 123 dispone un margen menor de discrecionalidad para los estados provinciales que, en virtud de la propia $\mathrm{CN}$, deben asegurar la autonomía de sus municipios no pudiendo optar por un régimen de autarquía como ocurría hasta antes de la reforma. ${ }^{9}$

En definitiva, a partir de los precedentes de la Corte Suprema se ha ido elaborando una doctrina que fue evolucionando con el tiempo hasta llegar a la postura actual e indiscutible de que los municipios, según el artículo 123 de la CN, son verdaderas entidades autónomas, con las limitaciones que surgen del artículo 5 de la Carta Magna. Seguidamente veremos las implicancias de esta afirmación en el plano tributario.

\subsection{Límites a la potestad tributaria ambiental de los municipios 4.2.1. Introducción}

A partir del reconocimiento constitucional de la autonomía municipal es lógico que autores como Rosatti (1997) se pregunten "cómo" y "con qué" los municipios pueden hacer efectiva su autonomía (p. 168), en el sentido de que por más que se les reconozca constitucionalmente su autonomía, es claro que sin recursos es imposible llevarla a la práctica. Es por ello que dicho reconocimiento implica una serie de facultades para ellos como la potestad para dictar medidas tributarias, entre los cuales podemos también ubicar a las de carácter ambiental. De manera que las provincias deben garantizar a sus municipios las atribuciones fiscales necesarias para dotarse de los recursos que le permitan asegurar su existencia y funcionamiento (Casas, 1998). Dicho esto, el siguiente paso consiste en fijar los contornos que limitan la potestad tributaria municipal y que nos derivan en el obstáculo formal que pretendemos esclarecer.

En primer término, es importante aclarar que esta potestad aglomera a las tres grandes categorías de tributos, ya sean vinculados o no, y todo tipo de finalidades, incluyendo las de carácter ambiental (extrafiscal). El hecho que los municipios habitualmente se hayan valido de tasas para financiarse (Álvarez Echagüe, 2005) no significa per se que sus atribuciones fiscales sólo se limiten a los tributos vinculados, como se creía tradicionalmente, sino que también alcanza a los impuestos y a las contribuciones ${ }^{10}$. El municipio "tiene competencia para crear cualquier clase de tributo que no se encuentre prohibida por una norma supranacional. Y esta normativa, a su vez, tiene límites que se desprenden de la propia Constitución Nacional" (Naveira de Casanova, 2001, p. 100).

${ }_{9}$ Esta cuestión se puede ampliar con las reflexiones de Álvarez Echagüe (2005).

${ }^{10}$ Esta postura es acompañada por autores de la talla de Jarach, Casas o García Belsunce. 
En segundo término, y a colación de lo anterior, la potestad tributaria municipal excluye la posibilidad de crear cargas cuya potestad esté expresamente limitada por el ordenamiento jurídico vigente, en especial la $\mathrm{CN}^{11}$ y el Derecho intrafederal. Este último es una fuente normativa tributaria de creación pretoriana, con jerarquía superior a las leyes nacionales, que comprende al régimen de coparticipación federal, los convenios multilaterales y pactos federales y su objetivo estriba en evitar la múltiple imposición por las consecuencias económicas que ello acarrea para la generación de riqueza en general y los contribuyentes en particular.

Recordemos que ni la CN (salvo en materia aduanera) ${ }^{12}$ ni la Corte (F. 210:276) vedaron la doble o múltiple imposición, pero las circunstancias demostraron que si no se pone una suerte de límite a la múltiple imposición se pueden derivar consecuencias económicas desastrosas y acabar vulnerando principios que sí están reconocidos en la Constitución, como el principio de no confiscatoriedad ${ }^{13}$. Teniendo en cuenta estos límites nos centraremos en aquéllos que surgen específicamente de la Ley de Coparticipación (23548), ya que es la norma infraconstitucional que actualmente genera mayores obstáculos a la hora de regular medidas tributarias municipales en general y de carácter ambiental en particular.

\subsubsection{Ley de Coparticipación Federal de Recursos Fiscales (23548)}

El sistema de coparticipación federal implica una serie de acuerdos entre la Nación y las provincias a los fines de distribuir las competencias para dictar tributos y la recaudación derivada de ellos ${ }^{14}$. Como bien señala Naveira de Casanova (2012), se trata de armonizar el ejercicio de competencias tributarias a nivel vertical dentro de la teoría del federalismo fiscal en donde "la participación en los ingresos tributarios obtenidos por otro nivel de gobierno implica un mecanismo de coordinación sobre la base de un impuesto único. En este caso, el nivel superior (la federación) establece un impuesto y, bajo ciertos condicionamientos, comparte su producido con otro nivel de Estado (las provincias)" (p. 98). De todas maneras, como veremos, también existe un reconocimiento de la potestad tributaria local. ${ }^{15}$

El principal objetivo de esta norma consiste en disminuir o neutralizar los efectos de la múltiple imposición. Para ello establecen una serie de recursos tributarios, en su mayoría im-

\footnotetext{
11 "no especifica... cuáles serán las potestades tributarias municipales, pero haciendo una armónica interpretación debemos poner en juego... la interrelación de los arts. 5 y 123 donde cada provincia dictará para sí una constitución y... garantizar el régimen municipal reglando su alcance y contenido en el orden institucional, político administrativo, económico y financiero" (Yatzkaier, 2008, p. 35).

${ }^{12}$ Artículo 75, incisos 1 y 2 de la CN.

${ }^{13}$ Reconocido en el artículo 17 de la CN.

${ }^{14}$ También es definido como "una herramienta de coordinación de competencias tributarias, articulada a través de acuerdos alcanzados a nivel político que se plasman en una ley federal dictada por el Congreso Nacional, que establece que lo recaudado... se repartirá conjuntamente con las provincias adheridas al sistema..." (Naveira de Casanova, 2012, p. 98).

${ }^{15}$ Concretamente en el artículo 9, inciso b), de la Ley 23548 cuando se deja a determinados impuestos en manos de las provincias al excluirlos de la regla de la prohibición de impuestos análogos.
} 
puestos, que conforman la llamada "masa coparticipable"16 y que son distribuidos entre la Nación y las Provincias (distribución primaria) ${ }^{17}$, por un lado, y luego entre las diferentes provincias (distribución secundaria) ${ }^{18}$, por el otro. Fuera de esa masa coparticipable existen tributos que le corresponde exclusivamente a la Nación ${ }^{19}$ y otros que son propios de las provincias. ${ }^{20}$

Como consecuencia de este acuerdo los estados provinciales asumieron, por sí y por sus municipios, una serie de obligaciones sin las cuales el régimen sería inviable ${ }^{21}$. Si bien es cierto que los municipios no son una parte específica de este acuerdo también es cierto que, en virtud de artículo 9, inciso b) de la Ley de Coparticipación, se encuentran sometidos a las mismas obligaciones que las provincias y es aquí cuando la potestad tributaria municipal se topa con ciertos límites que, lógicamente, también afectan a las medidas tributarias ambientales en el marco de los municipios.

Entre las diferentes obligaciones, una de las principales es aquélla que constriñe a las provincias "a no aplicar por sí y a que los organismos administrativos y municipales de su jurisdicción, sean o no autárquicos, no apliquen gravámenes locales análogos a los nacionales distribuidos por esta Ley. En cumplimiento de esta obligación no se gravarán por vía de impuestos, tasas, contribuciones u otros tributos, cualquiera fuere su característica o denominación, las materias imponibles sujetas a los impuestos nacionales distribuidos ni las materias primas utilizadas en la elaboración de productos sujetos a los tributos a que se refiere esta ley". ${ }^{22}$

A continuación la norma aclara que esta obligación no alcanza a las tasas retributivas de servicios efectivamente prestados (tributos vinculados) y a determinados impuestos que expresamente, y a pesar de estar inicialmente vedados a los entes locales, se excluyen de la prohibición antes mencionada (tributos no vinculados) ${ }^{23}$. De forma que los municipios tienen vía libre para regular tasas y contribuciones ambientales, siempre y cuando su denominación se corresponda fielmente con su contenido.

Las mayores limitaciones pasan más bien por el lado de los impuestos, y en este punto el quid de la cuestión pasa por interpretar los términos "análogos" y "materias imponibles" que menciona la propia normativa. Desafortunadamente, el articulado de la Ley 23548 no da ninguna definición ni demasiadas pistas sobre la manera de entender tales términos, así que hay que recurrir a la doctrina y jurisprudencia.

\footnotetext{
${ }^{16}$ Artículo 2 de la Ley 23548.

17 Artículo 3 de la Ley 23548.

${ }^{18}$ Artículo 4 de la Ley 23548.

${ }^{19}$ Artículo 2 de la Ley 23548.

${ }^{20}$ Concretamente, los impuestos provinciales sobre la propiedad inmobiliaria, sobre los ingresos brutos, sobre la propiedad, radicación, circulación o transferencia de automotores, de sellos y transmisión gratuita de bienes, y los impuestos o tasas provinciales y/o municipales vigentes al 31/12/84 que tuvieran afectación a obras y/o inversiones, provinciales o municipales dispuestas en las normas de creación del gravamen (Art. 9, inc. b), 3o párr., Ley 23548).

${ }^{21}$ Sobre la posibilidad que las Provincias restrinjan su poder tributario la Corte sostuvo que "el ordenamiento vigente en el país admite que las provincias puedan restringir convencionalmente el ejercicio de sus poderes impositivos mediante acuerdos entre sí y con la Nación, y la peculiaridad esencial de esos acuerdos, en lo que al caso interesa, es que no afectan derechos individuales" (F. 242:280).

${ }^{22}$ Artículo 9, inciso b), 10 y 20 párr., de la Ley 23548.

${ }^{23}$ Artículo 9, inciso b), 20 y 3o párr., de la Ley 23548 . Ver nota 41.
} 


\section{a) Analogía}

La incorporación de la prohibición de analogía en la Ley 23548 es consecuencia directa de la redacción de la Ley 14788 de $1959^{24}$, ya que hasta aquel entonces rigió la Ley 12956 de 1947 que hablaba de la prohibición de aplicar gravámenes “iguales” (Casas, 2007), lo cual evidentemente no es lo mismo. Según el Diccionario de la Real Académica Española (DRAE), la analogía es la "relación de semejanza entre cosas distintas", mientras que la igualdad es la "conformidad de algo con otra cosa en naturaleza, forma, calidad o cantidad"25. Es decir que existen mayores requisitos para que se configure el último caso que el primero.

A partir de la definición señalada vemos que la analogía es un concepto jurídico bastante impreciso e indeterminado pero que, como primera aproximación, implica algún grado de similitud (no exacta conformidad) entre distintos entes (Gianotti, 2011). El quid de la cuestión radica en definir cuándo existe tal similitud en materia impositiva.

Lamentablemente, la interpretación de la Comisión Federal de Impuestos no aporta demasiado, ya que concibe a la analogía como el fruto de una construcción doctrinaria y jurisprudencial que no se circunscribe a la perfecta coincidencia entre hecho imponible, base imponible y sujeto pasivo entre ambos tributos: el local y el nacional coparticipable. También agrega que el concepto va más allá de la estructura del tributo e incluye la función económica que éste está llamado a cumplir. ${ }^{26}$

Con mayor precisión Jarach (1966) sostuvo que, sin perjuicio de la valoración de las circunstancias particulares de cada caso, se entenderá que los impuestos locales son análogos a los nacionales unificados cuando se verifique alguna de las siguientes hipótesis:

“a) definiciones sustancialmente coincidentes de los hechos imponibles; b) definiciones más amplias que comprendan los hechos imponibles de los impuestos nacionales o más restringidas que estén comprendidas en éstos, aunque se adopten diferentes bases de medición; c) que a pesar de una diferente definición de los hechos imponibles, adopción de bases de medición sustancialmente iguales" (pp. 183-184).

Asimismo, el autor también aclara que no se descarta la analogía por la mera falta de coincidencia entre los contribuyentes, siempre que exista coincidencia sustancial, total o parcial, de hechos imponibles o bases de medición (Jarach, 1966).

Por su parte Gianotti (2011) afirma que si la finalidad del régimen federal de coparticipación estriba en "lograr una coordinación vertical entre los distintos entes dotados de potestad tributaria, esto es, nación, provincias y municipios" (p. 8), la prohibición de analogía debe 
verificarse fácticamente, no sólo normativamente. En caso contrario dicha finalidad podría verse vulnerada con el simple recurso de cambiar los términos lingüísticos de los elementos que componen un gravamen (Gianotti, 2011).

En un sentido similar la Corte sostuvo que para entender el término analogía hay que centrarse en los objetivos perseguidos por la Ley de Coparticipación en cuanto a evitar la doble o múltiple imposición interna. Luego de citar la postura ya mencionada de Jarach, la Corte afirma que "la analogía no requiere una completa identidad de hechos imponibles o bases de imposición, sino una coincidencia 'sustancial'. Tal criterio explica que el propio legislador dejase fuera del ámbito de la prohibición de analogía... a los impuestos sobre la propiedad, sobre la propiedad automotor, sobre los ingresos brutos, de sellos y a la transmisión gratuita de bienes" (P. 2738. XXXVIII).

\section{b) Materia imponible}

Este término está muy relacionado con la cuestión anterior y se refiere a la manifestación de capacidad contributiva que se pretende alcanzar con el gravamen. Desentrañar el significado de este término nos ayuda a entender en el caso concreto cuándo habrá analogía, ya que ésta depende del hecho que exista una misma materia imponible (P. 2738. XXXVIII) ${ }^{27}$. Coincidimos entonces con Gianotti (2011) cuando sostiene que la materia imponible se refiere:

“a la capacidad contributiva en su manifestación fenoménica, en directa referencia al plano fáctico sobre el cual se proyecta el concepto de analogía... es decir, sobre aquel hecho jurídico (comprensivo de los actos jurídicos) de contenido económico, o bien que evidencie la posesión de tal capacidad por parte de un sujeto determinado" (p. 5).

A partir de ello vemos que si bien los municipios conservan su potestad tributaria en materia impositiva dicha potestad parece estar reducida al mínimo, ya que la normativa prácticamente no deja materias imponibles para gravar (Álvarez Echagüe, 1999 y 2005). Desafortunadamente, esta situación también alcanzaría a los tributos ambientales.

No obstante, y para reivindicar la competencia tributaria de los municipios, entendemos que no habría impedimento alguno para que los municipios regulen impuestos (ambientales o no) con una imponible análoga a la del Impuesto a las Ganancias (IG) u otro impuesto nacional directo coparticipable en la misma situación. La CN concede a la Nación la facultad excepcional

\footnotetext{
${ }^{27}$ Tal es el caso del Impuesto Provincial sobre los Ingresos Brutos (IIB) y el Impuesto Nacional sobre el Valor Agregado (IVA), ya que ambos recaen sobre la misma materia imponible (Gianotti, 2011). También podríamos mencionar el caso del IVA y la Contribución Especial de la Provincia de Chubut por la que se gravaba el consumo de energía eléctrica en el ámbito provincial (Ley Provincial 4845 de 2002). La CSJN sostuvo que ambos gravámenes alcanzan la misma materia imponible: el consumo de energía eléctrica, sin importar que el impuesto nacional tiene un aspecto material y subjetivo más amplio que el provincial, ni que aquél grave la venta mientras que éste alcance el consumo, ya que en ambos la carga incide en quien adquiere el servicio (P. 2738. XXXVIII).

${ }^{28}$ Artículo 75, inciso 2, 10 párr., de la $\mathrm{CN}$.
} 
de dictar impuestos directos de manera temporal y "siempre que la defensa, seguridad común y bien general del Estado lo exijan" ${ }^{28}$. El IG, con diferentes denominaciones pero con la misma materia imponible, lleva vigente desde hace más de 80 años de manera ininterrumpida, violando el carácter excepcional y temporal que ordena la propia Constitución. Es por ello que mal puede el Estado Nacional invocar la prohibición de analogía frente a los entes locales basándose en la Ley 23548 (art. 9.b), cuando el impuesto nacional análogo, en este caso el IG, es abiertamente inconstitucional. Esta reflexión es válida para cualquier impuesto nacional directo que no respete los criterios constitucionales indicados y a través del cual se pretenda limitar la potestad tributaria municipal, lo que también incluye a las medidas tributarias ambientales.

\section{CONCLUSIONES}

En primer término, y en cuanto al obstáculo sustancial, vimos que las medidas fiscales ambientales son los tributos ambientales y beneficios fiscales ambientales. Los primeros son aquellos gravámenes que, sin despojarse de su afán recaudatorio, no persiguen esencialmente la obtención de recursos sino el desaliento de conductas o bienes que atentan contra el medio ambiente, sin importar la asignación presupuestaria de los fondos. Recordemos que estos gravámenes incluyen a las tres especies tributarias (impuestos, tasas y contribuciones especiales) y cada una deberá ser congruente con las exigencias propias de su especie y naturaleza jurídico-tributaria. Los beneficios fiscales ambientales son aquellas ventajas tributarias que persiguen anular, aminorar o aplazar el pago de un gravamen a los fines de incentivar la realización o utilización de actividades o bienes favorables con el medio ambiente.

En segundo término, y en cuanto al obstáculo formal, hoy en día existe consenso a la hora de afirmar que los municipios, según el artículo 123 de la $\mathrm{CN}$, son verdaderas entidades autónomas y que esta autonomía también se traslada al Derecho tributario concediéndoles, en principio, facultades para dictar toda clase de tributos, tanto ontológica como teleológicamente hablando.

No obstante, existen ciertas limitaciones a dichas facultades que derivan fundamentalmente del régimen de coparticipación ${ }^{29}$ federal y que influyen, en consecuencia, en el dictado de tributos ambientales. Estas limitaciones dependen de que se trate de un tributo vinculado o no a una actividad estatal específica.

Por un lado, en el caso de los tributos ambientales vinculados (tasas y contribuciones especiales) los municipios poseen amplias facultades para dictarlos y aplicarlos, siempre y

${ }^{29}$ Artículo 9 , inciso b), $2^{\circ}$ párrafo. 
cuando tales gravámenes estén efectivamente ligados a una actividad u obra municipal que, para que sean ecológicos, favorezca al medio ambiente.

Por el otro, en el caso de los tributos ambientales no vinculados (impuestos) la facultad para dictar impuestos ambientales encuentra mayores limitaciones, ya que éstos no podrán regularse cuando sean análogos a los impuestos nacionales coparticipables, es decir, en aquellos casos que existan semejanzas sustanciales en las materias imponibles alcanzadas. Para evitar estas limitaciones los impuestos ambientales deben alcanzar una manifestación de riqueza que tenga connotaciones contaminantes y que, a la vez, no sea análoga a la de un impuesto nacional coparticipado. Lo cual es sumamente complicado.

A partir de ello podemos decir que en materia de impuestos ambientales, la competencia municipal se encuentra prácticamente reducida al mínimo. Lamentablemente esta estricta limitación no sólo perjudica a las arcas locales, en el caso de los tributos recaudatorios, sino que además impide a los municipios, el ente de gobierno más idóneo para resolver los problemas ambientales de su jurisdicción, que puedan aprovechar la función disuasoria que comportan los impuestos ambientales respecto de determinadas conductas contaminantes. En los tributos ambientales vinculados esta posibilidad es prácticamente inexistente, ya que la realización del hecho imponible se centra en el Estado y no en los particulares.

No obstante, y más allá de las estrictas limitaciones señaladas, entendemos que las posibilidades competenciales de los municipios, tanto para tributos recaudatorios como ambientales, se mantienen cuando el impuesto local es análogo a un impuesto nacional directo coparticipado que no respeta los requerimientos del artículo 75 , inciso 2 , de la $\mathrm{CN}$, como es el caso, por ejemplo, de IG. Esto se debe a que mal puede el Estado Nacional invocar la prohibición de analogía frente a los entes locales, basándose en la Ley 23548, cuando el impuesto nacional análogo, que supuestamente impide legislar el gravamen local, es abiertamente inconstitucional. Vemos entonces que este incumplimiento constitucional sistemático del Estado Nacional respecto a ciertos impuestos directos permitiría a los municipios sortear algunas limitaciones competenciales legales (Ley de Coparticipación) y recuperar nuevamente parte de su competencia tributaria, aprovechándola para dictar impuestos ambientales de carácter directo.

De todas maneras, ésta no es una solución definitiva ni la más eficiente ecológicamente hablando, ya que deja totalmente fuera a los tributos ambientales indirectos y a los directos cuando el Estado Nacional sí cumple los requisitos constitucionales para dictarlos. Es evidente que nuestro sistema de coparticipación federal de ingresos públicos necesita ser íntegramente revisado, y ello también incluye la competencia tributaria municipal en materia ambiental. Una solución en este sentido podría ser mediante la reformulación, entre otras cuestiones, de la noción de "materia imponible análoga" cuando se trate de tributos ambientales (adecuadamente regulados), considerando que estamos ante competencias más ambientales que tributarias de los entes locales. 
En definitiva, sólo cuando los municipios puedan resolver y sortear las dificultades sustanciales y formales que obstaculizan el dictado de tributos ambientales, se allanará el camino para que puedan aprovechar las ventajas de la Tributación Ambiental y cuenten con una alternativa jurídica complementaria para enfrentar con mayor eficacia los problemas ecológicos que actualmente les aquejan.

\section{REFERENCIAS BIBLIOGRÁFICAS}

Almada, L. M. y Matich, C. (2011). Las tasas ecológicas en el ámbito municipal. Práctica Profesional (147), pp. 92-98.

Álvarez Echagüe, J. M. (2005). La potestad tributaria a partir del concepto constitucional de autonomía. Periódico Económico Tributario (332), pp. 1-5.

Álvarez Echagüe, J. M. (2001). Los municipios, las tasas y la razonable proporcionalidad entre lo recaudado y el costo del servicio. En José O. Casas (Coord.), Derecho Tributario Municipal (pp. 240-278). Buenos Aires: Ad-Hoc.

Álvarez Echagüe, J. M. (1999). Los municipios, su status jurídico y sus potestades financieras y tributarias en el marco de la Constitución reformada. Impuestos (LVII-B), pp. 2436-2468.

Ameriso, C., Beren, T., Ferullo, C. y Sevilla, J. (1999). Marco constitucional a la competencia ambiental de los municipios en materia tributaria. En 4 a Jornadas Investigaciones en la Facultad de Ciencias Económicas y Estadística (pp. 446-468). Rosario, Argentina.

Bidart Campos, G. (1994). Tratado Elemental de Derecho Constitucional. Buenos Aires: Ediar.

Bielsa, R. (1962). Principios de régimen municipal. Buenos Aires: Abeledo-Perrot; Casas, J. O. (1998). Naturaleza Jurídica de los municipios de provincia. Una trascendente modificación en la doctrina jurisprudencial de la CSJN (Causa 'Rivademar') y sus implicancias en el campo tributario (2da. Parte). Doctrina Tributaria Errepar (X), pp. 817-849.

Casas, J. O. (2007). Coparticipación y tributos municipales. Las tasas apócrifas y la prohibición de analogía, Ad Hoc, Buenos Aires, 2007. 
Cogorno, J. P. (2009). La matriz tributaria municipal. El límite provincial a la potestad municipal. Impuestos (13), 974-1001.

Díaz, V. (2008). Fiscalidad, extrafiscalidad y exenciones tributarias. Periódico Económico Tributario (1), p. 1-4.

Galarza, C. y Fraga, D. (2009, diciembre 4). Las haciendas locales ante el cambio climático a propósito de la aplicación de tributos 'verdes' en las municipalidades de España y la Argentina. El Derecho, Suplemento Tributario, pp. 1-6.

García Belsunce, H. A. (1995). La autonomía de los municipios provinciales en la reforma constitucional de 1994. Anales de la Academia Nacional de Ciencias Morales y Políticas (24), pp. 161-173.

Gianotti, G. (2011). Sobre la analogía en la Ley 23548: a propósito de un fallo del tribunal superior de justicia de Córdoba en la causa 'Laboratorios Raffo'. Periódico Económico Tributario (462), pp. 5-10.

Giuliani Fonrouge, C. M. (1993). Derecho Financiero. Buenos Aires: Depalma.

Herrera Molina, P. M. (2001). Metodología del Derecho financiero. Documentos del Instituto de Estudios Fiscales (26/o3), pp. 1-135.

Jarach, D. (1966). Coparticipación provincial en impuestos nacionales. Análisis y anteproyecto de ley. Buenos Aires: Consejo Federal de Inversiones.

Lepori, E. E. (2013). Potestad tributaria municipal. Especial referencia al municipio cordobés. La Ley Córdoba (septiembre), 815-820.

López Espadafor, C. M. (2007). La protección del medio ambiente y el impuesto sobre vehículos de tracción mecánica. Nueva Fiscalidad (1), pp. 47-80.

Lozano Cutanda, B. (2007). Derecho ambiental administrativo. Madrid: Dykinson.

Magadán, M. y Rivas García, J. (2004). Fiscalidad y medio ambiente en España. Oviedo: Septem-Ediciones. 
Naveira de Casanova, G. (2012). El concepto de analogía a los fines de la armonización tributaria en la Ley 23.548 de coparticipación federal de impuestos. Impuestos (8), pp. 90-112.

Naveira de Casanova, G. (2001). Competencias Tributarias de los Municipios. En José Casas (Dir), Derecho Tributario Municipal (pp. 349-363). Buenos Aires: Ad-Hoc.

OCDE (2001). Environmentally Related Taxes in OECD Countries. Issues and Strategies.

Revilla, P. (2001). El Impuesto sobre los Ingresos Brutos en la Ciudad Autónoma de Buenos Aires. En José Casas (Dir), Derecho Tributario Municipal (pp. 349-363). Buenos Aires: Ad-Hoc.

Rosatti, H. D. (1997). Tratado de Derecho Municipal. Buenos Aires-Santa fe: RubinzalCulzoni Editores.

Rozo Gutiérrez, C. (2003). Las funciones extrafiscales del tributo a propósito de la tributación medioambiental en el ordenamiento jurídico colombiano. Revista de Derecho (1), pp. 159-201.

Salassa Boix, R. (2013a). La empresa ante la adaptación a los efectos del cambio climático. En Susana Borrás Pentinat (Dir.), Retos y realidades de la adaptación al cambio climático. Perspectivas técnico jurídicas (pp. 293-319). Pamplona: Thomsom Reuters-Aranzadi.

Salassa Boix, R. (2013b). La finalidad extrafiscal de los tributos. Algunas notas sobre los tributos medioambientales. En Eduardo Arroyo (Dir.), Estudios de Derecho Tributario (pp. 155-198). Córdoba: Advocatus y Ciencia, Derecho y Sociedad (UNC).

Salassa Boix, R. (2013c). La tributación de la renta derivada del comercio de derechos de emisión de dióxido de carbono. Valencia: Tirant Lo Blanch.

Salassa Boix, R. (2015). Fiscalidad ambiental: nociones preliminares. En Rodolfo Salassa Boix (Dir.), La protección ambiental a través del Derecho fiscal (pp. 21-45). Córdoba: Advocatus y Ciencia, Derecho y Sociedad.

Schindel, A. (2003). Concepto y especies de tributos. En Horacio García Belsunce (Dir.), Tratado de tributación. Derecho tributario, Tomo I, Vol. 1 (pp. 565-622). Buenos Aires: Astrea. 
Varena Alabern, J. E. (2010). Extrafiscalidad irregular e imposición inmobiliaria. Quincena Fiscal Aranzadi (1), pp. 67-95.

Yatzkaier, S. (2008). Potestades tributarias municipales. Práctica Profesional (84), pp. 32-70.

\section{JURISPRUDENCIA}

CSJN, "Boffi, Leopoldo L. c/ Provincia de Buenos Aires”, de 3 de marzo de 1948 (Fallos: 210:276).

CSJN, “Compañías de Seguro Industria y Comercio y La Rosario c/ Municipalidad de Rosario”, de 18 de agosto de 1944 (Fallos: 199:423).

CSJN, "Municipalidad de General Pueyrredón c/ Jockey Club de Mar del Plata”, de 27 de febrero de 1929 (Fallos: 154:25).

CSJN, “Municipalidad de La Plata c/ Ferrocarriles del Sud”, de 1 de junio de 1911 (Fallos: 114:282).

CSJN, "Rivademar Ángela Digna Balbina Martínez Galván de c/ Municipalidad de Rosario s/ recurso contencioso administrativo, de 21 de marzo de 1989 (Fallos: 312:327).

CSJN, "Madariaga Anchorena Carlos Juan”, de 21 de noviembre de 1958 (Fallos: 242:280).

CSJN, “Pan American Energy LLC. Sucursal Argentina C/ Provincia de Chubut”, de 19 de junio de 2012 (P. 2738. XXXVIII).

\section{CURRICULUM VITAE}

\section{Rodolfo Salassa Boix}

Abogado por la Universidad Nacional de Córdoba, Argentina (UNC). Magister en Derecho de la empresa y la contratación y Doctor en Derecho (mención europea) por la Universidad Rovi- 
ra i Virgili de Tarragona, España (URV). Profesor de grado y postrado en Derecho tributario en dichas universidades. Investigador del Conicet. Pro-Secretario de Ciencia y Técnica y Director de la Editorial Ciencia, Derecho y Sociedad de la Facultad de Derecho de la Universidad Nacional de Córdoba, Argentina. Director del proyecto de investigación titulado "La Fiscalidad Ambiental en el ordenamiento jurídico argentino a partir del marco de la Constitución Nacional” (2016-17), dirigido por el Dr. Rodolfo Salassa Boix y aprobado y financiado por la Secretaría de Ciencia y Tecnología de la Universidad Nacional de Córdoba, Argentina (Secyt).

rodolfoboix@gmail.com 